\section{Bodas de disciplina. De la parasitación ontológica de las mujeres familiares de personas privadas de libertad}

Disciplinary weddings. On the ontological parasitization of female relatives of people deprived of freedom

Pablo Hoyos González

\section{RESUMEN}

A la institución carcelaria le sigue interesando la familia, si no, qué hay de la organización de bodas multitudinarias adentro del penal, o la facilitación de los permisos de visita mediante el acta matrimonial. En el presente artículo realizaremos una aproximación genealógica al estilo foucaultiano, en la que se analizarán las superposiciones, las porosidades y los límites en las relaciones entre el poder disciplinar y la familia burguesa desde mediados del siglo XVII. Veremos cómo el poder disciplinar fue extendiendo sus injertos, disciplinando las formaciones soberanas, en la consolidación de la producción capitalista en Occidente, hasta componer una red de control sobre la familia a cambio de hacerla una "pequeña célula intensiva" responsable de la formación productiva y moral de sus miembros. Desde las instancias del continuum disciplinar se intervendrá a la familia, hasta el límite de secuestrar a uno de sus miembros para atender su indisciplina lejos de la célula familiar, corresponsabilizada ésta de la desviación conductual de su integrante. Tomaremos el caso de la cárcel -cúspide de la pirámide disciplinar- y prestaremos especial atención a las consecuencias del encarcelamiento, en específico a sus efectos subjetivantes sobre las mujeres familiares de los internos, haciéndolas prenda de una deuda ontológica que transforma su tiempo de vida en tiempo de deuda, intensificando su ocupación productiva y reproductiva.

Palabras clave: cárcel; mujeres; poder disciplinar; subjetivación

\section{ABSTRACT}

The prison institution is still interested in the family, if not, what about the organization of mass weddings inside the prison, or the facilitation of visiting permits through the marriage certificate. In this article we will take a Foucauldian-style genealogical approach, analyzing the overlaps, porosities and limits in the relationship between disciplinary power and the bourgeois family since the middle of the seventeenth century. We will see how disciplinary power was extending its grafts, disciplining sovereign formations, in the consolidation of capitalist production in the West, to the point of composing a network of control over the family in exchange for making it a "small intensive cell" responsible for the productive and moral formation of its members. From the instances of the disciplinary continuum, the family will be intervened, up to the limit of kidnapping one of its members to attend to his indiscipline far from the family cell, the latter being coresponsible for the behavioral deviation of its member. We will take the case of prisonthe apex of the disciplinary pyramid-and pay special attention to the consequences of imprisonment, specifically to its subjectivizing effects on the female relatives of the inmates, making them the pledge of an ontological debt that transforms their time of life into time of debt, intensifying their productive and reproductive occupation.

Keywords: Prision; womens; disciplinary power; subjectivation

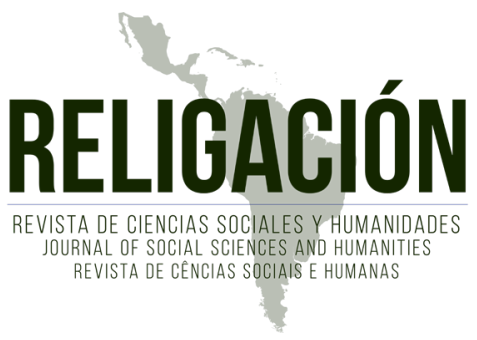

INFORMACIÓN:

http://doi.org/10.46652/rgn.v6izo.853 ISSN $2477-9083$

Vol. 6 No. 30, 2021. e210853 Quito, Ecuador

Enviado: octubre 08, 2021

Aceptado: diciembre 12, 202

Publicado: diciembre 17, 2021

Publicación Continua

Sección Dossier | Peer Reviewed

\section{AUTOR:}

(1) Pablo Hoyos González

Universidad Autónoma Metropolitana, sede Izapalapa - México

phoyos@izt.uam.mx

\section{Conflicto de intereses}

El autor declara que no existe conflicto de interés posible.

Financiamiento

No existió asistencia financiera de partes externas al presente artículo.

Agradecimiento

$\mathrm{N} / \mathrm{A}$

Nota

El artículo no se desprende de un trabajo anterior.

ENTIDAD EDITORA 
1. Breves apuntes genealógicos de la pequeña célula familiar en la emergencia del capitalismo industrial occidental

En la afluencia de la trashumancia del campo a la ciudad, las familias campesinas caminan fragmentadas por veredas cercadas que dan cuenta de la expropiación y la privatización de las tierras, caminan entre vagabundos que odian el trabajo asalariado y se rebelan contra él (Federici, 2004). Vagan junto a jaurías de niños expósitos cobijados in bando, buscándose la vida sin la constancia ni la permanencia que el trabajo fabril amerita, y comenzando a engrosar las filas de la naciente delincuencia urbana que será ardid fundamental del asentamiento del capitalismo y del estado burgués.

Con el fin de combatir el nomadismo y el vagabundeo, así como para retener a las incipientes cuadrillas de obreros, la burguesía industrial de la mano de las nacientes disciplinas científicas diseñan todo un continuun de instancias disciplinares, una serie de engranajes espaciotemporales, técnicas y procedimientos, donde la vida de los proletarios quedará sujeta al tiempo de la producción y la ganancia, y sus cuerpos se transformasen en parte sustancial de la maquinaria productiva, "un tiempo que ya no era el de la existencia de los individuos, sus placeres, sus deseos y su cuerpo" (Foucault, 2016, p. 247). Las instancias disciplinares conforman un sistema de transmisión del saber-poder que se coloca "en el seno de un aparato sistemático del poder judicial, político o económico” (Foucault, 2011, p. 142).

Con el cuerpo de los obreros en la mira, desde la filosofía mecanicista de Descartes, el nuevo espíritu burgués, se empeña en el producir un saber sobre el cuerpo social que le permita dominarlo. Busca racionalizar su operatividad enfocando sobre el mismo una mirada intensiva que trata de hacerlo inteligible, controlable. Las instancias disciplinares trabajan a partir del secuestro parcial de sus integrantes sobre un esquema de vigilancia que ahorma, apuntala, sujeta a los individuos al tiempo de la producción y de la ganancia tanto a través de un régimen productivo, como de una ortopedia improductiva que le va a servir de contraparte, estas son las instancias pedagógicas, correctivas y terapéuticas. Los secuestros discretos en cada una de estas instancias, proveen a los individuos de formas de emplear su tiempo en un espacio aislado donde un corpus de empleados -desde expertos hasta celadores- lo observarán minuciosamente vigilándolo a la vez que lo estudiarán como objeto de conocimiento. Una mirada que parte de "la base de un análisis del proceso social de naturaleza esencialmente mecanicista” (White, 2001, p. 55), buscando las regularidades y las diferencias, a partir de las cuales construir divisiones y jerarquías de raza, de género, de edad, las cuales "se hicieron constitutivas de la dominación de clase y de la formación del proletariado moderno" (Federici, 2004, p. 90).

El cuerpo será la diana, el centro de un ejercicio de racionalización que pasa por sujetarlo a la producción y al salario, queriendo maximizar su utilidad social. Un cuerpo que quiere ser reducido a herramienta, a mecanismo, engranaje de la cadena de montaje fabril, un cuerpo domesticado de su sensibilidad y de su fiereza (Nietzsche, 2019). Un cuerpo del tiempo de la producción, de la ganancia, un cuerpo homogeneizando por la probabilística coreografía de la rutina. En definitiva, un cuerpo colonizado por la razón y las ideas, avasallado por un alma nueva que lo cautivará en la arquitectura transparente del ideal (Lagarde, 2015). Que lo unificará y lo fijará en un yo, en una identidad estable, congruente y verosímil con el historial de actividades 
productivas y reproductivas. Una identidad que lo respaldará como una torre de discos duros, y que lo hará responsable de sí mismo hasta la muerte.

Para engarzar el tiempo de producción y el de la ganancia, para hacer a los obreros "amos del tiempo" (Irigaray, 2010, p.37), se les enseñó “una cualidad que se denomina previsión” (Foucault, 2016, p. 246). Para que asumieran el control del drenaje de su salario y direccionaran su deseo hacia un momento ulterior, un porvenir, un futuro del que sin saberlo ya eran propietarios y que tendrán que ocupar de imaginaciones a las que aspirar dar realización. El ideal burgués, investido por el patrón industrial, quería que el obrero en lugar de gastar su salario en "el azar de su existencia”, se pusiera a pensar qué hacer con su tiempo de vida, cómo ejercitar y ejercer la libertad que, como muestra Simmel, le había “regalado" el régimen del salario, pues “la forma del salario en dinero garantiza al trabajador, le concede una libertad completamente nueva, dentro de sus ataduras" (2016, p. 349). El ideal burgués quería que su trabajador comprara futuro/deuda, en lugar de carnaval e inmanencia, en este tenor se introdujeron las cajas de ahorros para fraguar la conversión del tiempo de producción en tiempo de ganancia, para que termináramos de incorporar la naturalizada metáfora es que reza que el tiempo es oro.

\subsection{La organicidad de la familia privatizada}

La insistencia de la burguesía industrial en la fijación de los obreros en la continuidad del tiempo de producción y de ganancia, precisó expropiar la forma de la familia noble y cortesana, privatizándola y reconstituyéndola en una forma acorde con una concepción organicista de las comunidades humanas típica de la ilustración: la "pequeña célula familiar" (Foucault, 2007, p. 118). Una nueva infraestructura familiar intensiva, concentrada y delimitada, que, como expone Federici, va a ser "complemento del mercado, instrumento para la privatización de las relaciones sociales y, sobre todo, para la propagación de la disciplina capitalista y la dominación patriarcal" (2004. p. 149).

Frente a los códigos dominantes de la nobleza cortesana que consideraba innoble la unión del amor y del matrimonio (Alvarez-Uria y Varela, 1991, p. 136), como señalara Engels, la "argamasa de la célula" se funda en la libre elección "que deviene del amor, de la libertad del amor, (...), que tiene la consigna moral de persistir indisoluble” (2016, p. 252). Célula palpitante, insólita “esfera de intimidad" (Adorno \& Horkheimer, 1969, p. 137), cerrada sobre si, bardeada en la sexualidad monógama, e intensificada en una división sexual del trabajo por la que las mujeres van a ser relegadas del trabajo asalariado, quedando obliteradas y estampadas en la figuración “de la ama de casa a tiempo completo" (Federici, 2004. p. 112), haciéndolas cautivas del trabajo reproductivo (Lagarde, 2015).

La familia es una micro célula perteneciente a un organismo superior, a la célula Estatal. A través de la familia, la matriz estatal va a empuñar sus combates contra la irracionalidad, el deseo al ocio y el pensamiento mágico. Como apuntaran Adorno y Horkheimer, "sólo la familia podía hacer surgir en los individuos la identificación con la autoridad, como ética del trabajo, que reemplazó funcionalmente a la potestad inmediata sobre los siervos de la precedente época feudal" (1969, p. 137). Garante de la libertad, la familia va a cuidar a sus componentes como 
miembros de un mismo clan empresarial, los va a formar en la ética del trabajo y en la previsión, prometiéndole al Estado que cada uno de ellos se constituirá en fuerza productiva y hará libre ejercicio de su salario.

Aún a mediados del siglo XIX, tras la difusión de los trabajos de Darwin, la familia fue presentada como uno de los vectores fundamentales de la empresa civilizatoria. Por aquel entonces el modelo familiar se utilizó tanto para profundizar en el neocolonialismo europeo como vector de organización de la vida de los pueblos colonizados dentro de un esquema militar, así como para distribuir a los vagabundos asilvestrados, a las mujeres embrujecidas y a los locos asalvajados frente a aquellos blancos hombres burgueses que gobernaban y se conducían a través de la razón. Con la finalidad de "ayudar" a esta población rezagada en el subdesarrollo moral fueron diseñadas instituciones asilares entre cuyas paredes se replicaba la escenografía de un contexto "cuasi familiar", que por su propio atrezo ostentaban un valor remedial para reencauzar una desviación atribuida a la ausencia de dirección y de estructura familiar (Foucault, 2007).

Pero como veremos más adelante, el valor estructurante y correctivo de este esbozo familiar sentirá la presión de las instancias disciplinares, las cuales comenzarán a hacer cuña en la “pequeña célula familiar” poniéndola en una deriva actualizadora.

1.2 La "soberanía disciplinada" de la pequeña célula familiar. Los injertos del continuum disciplinar y la labor de los hábitos como producción de la norma productiva

A mediados del s. XIX la familia ha sido enclavada en las ciudades obreras, un espacio habitacional anexo de la fábrica, una extensión de la misma que sirviera como dormitorio y repositorio de las fuerzas productivas. Desde el enclave sedentario, comienza a entrar en contacto con toda una multiplicidad de instancias disciplinares -la fábrica, la caja de ahorros, la escuela, el batallón, el asilo, la cárcel. Se trata de un continuum disciplinario con el que los individuos sostienen distintos tipos de relación a diferentes niveles de intensidad durante toda su vida, y donde a su vez cada miembro forma parte de su entramado sin que ninguna de ellas exactamente le represente (Foucault, 2016, p. 239).

Es decir, la afluencia de los injertos de instancias y técnicas disciplinares van construyendo efectos de disciplinamiento en la célula familiar, van generando una "soberanía disciplinada", una "disciplinarización interna, cierta transferencia, en el seno mismo del juego de soberanía familiar, de las formas, los esquemas disciplinarios" (Foucault, 2007, p. 142). De este modo, los entre la familia y la disciplina, parasitan la soberanía familiar, transformando su protagonismo anterior como dispositivo colonial y civilizatorio, en una "arquitectura de luz" (Deleuze, 2013) donde la familia se convierte en la simiente del régimen disciplinar en tanto que, desde su carácter soberano, soportan la inserción a las instancias disciplinares, así como son continente y germen de las indisciplinas.

De las ligazones recurrentes, se va construyendo diacrónicamente un tejido de hábitos, los cuales se van a acompañar de un discurso que va a "describir, analizar, fundar la norma y hacerla prescribible, persuasiva" (Foucault, 2016, p. 276). Será a través de la norma, y todo un juego de coerciones y castigos, aprendizajes y sanciones que los individuos van a ir quedando fijados a los aparatos de producción. Normatividad que les liga a "un orden de las cosas, un 
orden del tiempo y un orden político" (Foucault, 2016, p. 274). Como representante del Estado, la familia es la encargada de cercar el flujo de los deseos de rebeldía y de ociosidad, de castigar la indisciplina, la insubordinación, así como de subordinar a sus mujeres a la autoridad patriarcal. La familia ha de educar, vigilar y castigar la incorporación de los hábitos disciplinares, ha de subirse al paradigma de la mirada vigilante y examinadora, la mirada panóptica. Y contantemente examinar, evaluar, premiar, castigar y corregir, a cada uno sus integrantes para mantenerlos dentro de la senda de normativa de los hábitos productivos.

\subsection{El injerto de la mirada panóptica en la mácula familiar}

La mediación de la mirada panóptica es uno de los engarces fundamentales con los que opera el injerto disciplinar para parasitar la soberanía familiar (Foucault, 2007, p. 143). La inserción de la mirada panóptica supone una mediación cuyo efecto es la intensificación de lo real. Una mirada que nos permite ir del concepto al caso particular y viceversa con una coherencia y una congruencia lógica que no tolera agrietamientos. La fuerza del panóptico se construye, en la microfísica de un poder de una mirada cargada de enunciados de cuyo output resulta una verosimilitud respaldada por la extracción selectiva de unas observaciones, de un saber, que producen un poder. La mirada panóptica forma, reforma, corrige, desde un quiasma compuesto por el poder económico, el poder político y el poder judicial. Una mirada polivalente que “da órdenes, toma decisiones, garantiza funciones -tales como la producción o el aprendizajey también juzga, tiene el derecho de castigar y recompensar "o de hacer comparecer ante instancias de enjuiciamiento" (Foucault, 2011, p. 142). Zona gris, en la que se va a poner a la familia detectar la desviación y la anormalidad, prestando atención densa a la más mínima acción cotidiana, al más mínimo gesto, constituyendo a sus integrantes en “individuos a la vez portadores y receptores de realidad" (Foucault, 2007, p. 225).

La identidad forma parte de este juego de continuidades y regularidades que insiste en producir el panoptismo, la de fijar a la persona en la producción de un yo "que pueda responder por sí mismo a través del tiempo" (Butler, 2011, p. 86). El yo encuentra su primera chispa, su primer resplandor en la necesidad del contrato mercantil por darle mayor musculatura al acto de habla de la promesa, tal y como expone Nietzsche (2019), en su tesis sobre el origen de la subjetividad en la relación indisociable entre la deuda y la culpa.

Voy a poner un ejemplo escolar, para a través de la cuña familia-escuela (Herrera Urízar, 2019), se entienda el injerto panóptico. En la cuña familia-escuela vemos que los padres no sólo exhortan a los hijos a asistir, sino que los preparan, los llevan, les exigen, dan seguimiento, y, evalúan su desempeño. La cuña familia-escuela genera prolíficos efectos en los afectos de la célula familiar, en su ánimo, en la distribución de las labores, en el empleo del tiempo, etc. La familia y la escuela no son entidades estancas, están puenteadas por un régimen de actividadproducción y un dispositivo de examen. Respecto del régimen de actividad-producción, concierne la participación de los tutores en la organización asociativa con sus pares (Asociación de Padres de Alumnos), como en actividades escolares como las juntas, las clases muestra o los festivales. El régimen productivo de la escuela no sólo reclama a los tutores adentro, sino que trasvasa su agenda de actividades al hogar, ya sea con la tarea, la recaudación de 
materiales, los hábitos de higiene, de alimentación, etc. Sobre el dispositivo de examen, la escuela sostiene una economía de premios y castigos, que despliega ritualmente a través de las evaluaciones y que objetiviza en las calificaciones. Éstas son el hito, el testigo que une las manos. Si son negativas, el llamado de atención es tanto para el estudiante como para la familia, pues ésta será conminada a tomar medidas que estructuraran el tiempo extraescolar, ya sea en el calendario escolar o durante las vacaciones. La presión de la cuña disciplinar pone a los niños en la "lógica natural" de la competencia consigo y entre sí, y hace de los padres un relevo más en la omnipresencia de la mirada panóptica, una intromisión imperceptible que nos hace escudriñar a los demás integrantes de la célula familiar como padres-jueces, padres-maestros, padres-psicólogos. Sagazmente, Foucault apunta que la familia opera como "una microcasa de salud, que controla la normalidad o la anomalía del cuerpo y el alma” (2007, p. 143). Donde en la distribución de funciones celulares, "todos hacen reinar la universalidad de lo normativo, y cada cual en el punto en el que se encuentra, le somete el cuerpo, los gestos, los comportamientos, las conductas, las actitudes, las proezas" (Foucault, 2015, p. 355).

\section{Método}

El artículo se propone como una reflexión sociológica de índole teórico, que deviene del trabajo empírico realizado, entre 2014 hasta la fecha, a partir de la metodología de las narrativas (Chase, 2015). Un trabajo empírico ubicado en la simiente de los conocimientos situados (Biglia y Bonet Marti, 2009), en el que construimos una agenda de investigación colaborativa con una familia de cuatro integrantes que mantendremos en anonimato por decisión propia, y con quienes, tras darle varias vueltas, optamos por diseñar un método de producción de narrativas a través del dibujo (Hoyos, 2021). El andamiaje teórico del artículo es pues una deriva reflexiva del autor desde la compañía epistémica (Scheurich, 1995) de las y los coinvestigadores, la madre y la hija, y el padre y el hijo, donde la figura paterna fue la que estuvo dentro de la prisión por un lapso de 10 años.

\section{La parasitación de la pequeña célula familiar. La función psi y su digestión refamiliariza- dora}

Como vimos, la familia pasó de ser la receta para la cura, a ser parte fundante del problema, caldo de cultivo e invernadero de la desviación y la anormalidad. Debido a su total implicación en la indisciplina, en caso de no ejercer positivamente sus labores de irrigación, sostenimiento y control en el continuum disciplinar de sus miembros, y con la excusa punitivista de "evitar el mal mayor" (Baratta, 2016), es que las instancias disciplinares injertadas en la célula familiar tienen la potestad de impugnarla. Tal impugnación se enmarca en un proyecto biopolítico extenso en el que se apuesta por la reinserción del desviado como reajuste a la normatividad de la matriz productiva.

La insuficiencia disciplinar es la llave reguladora de la intensidad con la que las instancias disciplinares han de gestionar la desviación para aplicar sobre ellas su poder positivo. Todo un andamiaje no productivo de índole correctivo que va a parasitar a la familia mediante el despliegue de distintos procedimientos, técnicas, profesionales e instrumentos que van a examinar el 
grado de intensidad de la indisciplina específica, y tomar las medidas correspondientes. Estas instancias correccionales van a funcionar como la contracara de la familia, pues a través de su "función psi", se va a remitir al discurso de la familia a la vez que van a poseer el cuerpo de su miembro para aplicarle un intensivo disciplinar lejos de las sinapsis familiares. Es el corpus teórico de todo dispositivo disciplinario. "La función psi (...) es la instancia de control de todas las instituciones y de todos los dispositivos disciplinarios al mismo tiempo emite, sin contradicción alguna, el discurso de la familia" (Foucault, 2007, p. 111). Se refiere a las instancias psiquiátrica, psicopatológica, psicosociológica, psicocriminológica, psicoanalítica, etc. Paradoja que va de la orden de sustraer, apartar, aislar, "dejar en suspenso todo lo relacionado con configuraciones, puntos de apoyo, relevos propios del poder familiar" (Foucault, 2007, p. 122), a promover la instancia disciplinar como un espacio estanco que permite la refamiliarización. Contradicción que muestra el permanente juego de remisiones entre la familia y el dispositivo disciplinar.

\subsection{La idiosincrasia de la cárcel como cúspide de la pirámide disciplinar, y sus inscripciones en los secuestrados}

El sistema legal priva de la libertad, encarcela. Pero su operador ortopédico, la racionalidad correctiva es una empresa extralegal, que como advierte Foucault, homogeneiza los castigos legales con los mecanismos disciplinarios, "naturaliza el poder de castigar y legaliza el poder técnico de disciplinar” (2009, p. 354). La cárcel se encuentra en la cúspide de la pirámide disciplinar, lo que la diferencia la cárcel de las demás instituciones del continuum disciplinario es tan sólo una cuestión de gradación y de intensidad. Siguiendo a Foucault,

...en su función, este poder de castigar no es esencialmente diferente del de curar o al de educar. Recibe de ellos, y de su misión menor y menuda, una garantía de abajo; pero que no es menos importante, ya que se trata de la técnica y la racionalidad (2009, p. 354).

Como muestra Pavarini, la pena privativa de la libertad hace sentido en el marco del contexto productivo, en el que "la libertad adquirió un valor económico" (2016, p. 36). La libertad es la medida temporal que trabaja como valor de cambio ante la forma de desviación delincuencial, ya que el individuo no ha sido capaz de ejercerla adecuadamente sosteniendo en un umbral adecuado su autodisciplina, autocontrol y autorregulación. El castigo opera en la transformación del tiempo de ganancia al tiempo de deuda, que obstruye la promesa del "tiempo como riqueza" (2016, p. 37). La deuda se presenta como fruto naturalizado de la indisciplina, como una contracción que es acto reflejo del cuerpo social, naturalización que asienta que se es libre en la medida en que se asume un modo de vida (consumo empleo, erogaciones sociales, impuestos, etc.) que "ha de ser compatible con el reembolso" (Lazzarato, 2013, p. 37). En definitiva, como si el acto reflejo de la contracción -de la deuda- no respondiera a una implacable insistencia represiva de las indisciplinas.

La detención legal enmarca al encarcelado y lo forma primero la matriz discursiva de un sujeto jurídico, así como lo hace aparecer "como signo de culpabilidad y transgresión, como encarnación de la prohibición y la sanción en los rituales de normalización” (Butler, 2011, p. 96). El encarcelamiento es una determinada manera de secuestrar y acumular cuerpos en un espacio de encierro bajo la ceremonia insidiosa y permanente del examen, técnica que entrecruza la 
sujeción y la objetivación, una “dominación-observación” (Foucault, 2015, p. 356) que establece una relación definida entre el saber y el poder desde la que se va a construir un juego de veridición y objetivación. Labor escritural que va a consistir en una:

...superposición de $\mathrm{co}(\mathrm{r})$ pos, envoltura de inscripciones donde la persona ahora podrá encontrar sus estigmas delincuenciales, mirarlos, tocarlos, reconstruir una y mil veces su historia, esa mi piel donde ahora encuentro los rasgos y caracteres del delincuente que he de ser, donde el lunar, la cicatriz, el tatuaje ahora son inculpatorio-probatorios, y en las sucesivas narraciones biográficas [escucho la verdad de mi alma] (Hoyos, 2021, p. 278).

3.2 La creación de la deuda ontológica: El incumplimiento familiar de la promesa de inserción en la matriz productiva

El delincuente no se hizo solo, en parte es consecuencia del incumplimiento de la promesa disciplinar de su familia. El fracaso correctivo de la célula familiar escribe la sentencia de su condena. La responsabilidad de la indisciplina se trasvasa del sujeto jurídico a la célula familiar, cargada en su origen histórico como el embrión de las indisciplinas, se la reprende por su incapacidad de regular la frecuencia de las transgresiones, así como de no haber extinguido las expresiones destructivas de sus miembros.

Al incumplir su promesa disciplinar, la familia pierde su garantía, aquella que el Estado le había otorgado, y pasa a convertirse en deudora, en tanto que "el deudor es aquel que no logra cumplir su promesa, prolongar su voluntad y cumplir su palabra con la ejecución de un acto" (Butler, 2011, p. 85). La familia ha de ser castigada por su incumplimiento, se la convierte en "prenda" de la deuda contraída por su miembro encarcelado, porque, además, ésta es lo único que a éste le queda. Las penas son colectivas, aunque únicamente en la sentencia quede rubricado el nombre del familiar, los apellidos están escritos con el mismo pulso punitivo y con la misma tinta correctiva.

Cómo veíamos en el funcionamiento de las instancias correctivas, la disciplina que vienen a enderezar las indisciplinas tiene un destino familiar, un retorno a la célula familiar. La corrección dispone un regreso a la familia, una refamiliarización que va a operar a través de un doble mecanismo el trabajo intensivo sobre el desviado, y por otro, sobre la imposición de una deuda ontológica por el incumplimiento de su promesa, una deuda que la impone la persistencia de una existencia precaria (López Petit, 2009; Lorey, 2016). La refamiliarización, como expone Ferreccio, va a generar un "efecto re-tradicionalizador (...) en la división de roles familiares" (2018, p. 54), sobrecargando a las mujeres en la exponencialización productiva y la reproductiva. La deuda familiar no hace, sino que los injertos disciplinares regresen con furia transformando el tiempo de la ganancia en tiempo de deuda. Tal transformación, genera una apropiación ontológica, una parasitación que, como sostiene Lazzarato:

...se apropia no sólo del tiempo cronológico del empleo, sino también de la acción, del tiempo no cronológico, del tiempo en cuanto elección, decisión, apuesta sobre lo que va a suceder y sobre las fuerzas (confianza, deseo, coraje, etc) que hacen posibles la elección, la decisión, el obrar y los explota (2013, p. 63). 
En su generización, la re-familiarización toma como "prenda" a la celularidad femenina de la familia, así el sistema legal va a ligar las condiciones de liberación a diferentes modos de seguimiento examinador sobre los modos de conducción de las familiares endeudadas. Desde el eco soberano de los lazos de sangre se ata la existencia de las mujeres a los ciclos de producción, se le exhorta a hiper convertir su vida en producción, forjando el hábito normativo que "es el complemento del contrato para quienes no están ligados al orden de la propiedad" (Foucault, 2016, p. 274). Lo que dilucida la cárcel como un invento del Estado burgués dirigido especialmente a las familias obreras, a los pobres, tal y como evidenciara Wacquant (2010), así como la precarización como una de las funciones principales de la pena (Baratta, 2016). La cárcel es un campo de batalla intensivo, una locación más entre toda una red de otros dispositivos carcelarios que buscan plegar la fuerza social normalizándola en torno a los aparatos de producción.

\section{La parasitación ontológica del encarcelamiento como dispositivo de subjetivación de las mu- jeres familiares}

La "deuda" penitenciaria conlleva la instalación del sujeto, una subjetivación (Ramírez Zuluaga, 2015; Mendieta, 2021), vuelve sobre sí a las familiares “en libertad” con la transformación del tiempo de ganancia en tiempo de deuda. El tiempo de vida se transforma en tiempo de deuda, las mujeres deben la vida, su vida, y como apunta Butler, en virtud del miedo y del terror es que "empezamos a reflexionar sobre nosotros mismos" (2009, p.23). Un dolor que como nos dice Deleuze, "sólo paga los intereses de la deuda; el dolor está interiorizado, la responsabilidad se ha convertido en responsabilidad-culpabilidad" (2013, pp. 198-199).

Las mujeres de la familia pagan su tiempo de deuda trabajando de sol a sol, tanto para poder sostener los numerosos costos del encierro, como para poder subsistir, quedando en el horizonte cotidiano el dibujo de un porvenir que no será sino fruto de un esfuerzo indiscreto y exponencial, de una "proeza" disciplinante. Atrapadas en un esclavismo en libertad, donde las ocupaciones irían limpiando la pena y la deuda con el sudor de la frente, los cuerpos de las mujeres son subordinados y sometidos a una intensificación productiva y reproductiva que lo sobrecargan y lo desgastan. Se trata de una fuerza gravitatoria que se cierne sobre sus espaldas, sus hombros, sus rodillas; una fuerza que es el epítome de un castigo que, en lugar de indirecto, es transversal, extensivo, “orgánico". Un dibujo del porvenir en el que ni se intuye el final de la deuda, para el que el pago se realiza incrementando y sosteniendo la cantidad de ocupación y de empeño, llevando al éxtasis el aguante. Una demanda tremenda que exige que la fuerza productiva no fenezca en los titubeos del cansancio, la desesperación y el resentimiento, que, según Deleuze, es la reacción que al dejar de ser accionada "se va digiriendo en algo sentido, (...) va dejando huellas mnémicas” (2013, p. 158). La carga de la intensificación productiva evoca una memoria que las interpelará sujetándolas, que las interrogará desde el marco interpretativo del juicio, pugnando por sustituir su voz "propia”, y disuadiéndolas de la fuerza activa del olvido, a partir de la cual, indica Deleuze, podemos refrescar, dar fluidez y permitirnos acercarnos a la serenidad, la esperanza o el orgullo (2013, pp. 159-160). 
Huellas mnémicas de cuya interpelación emana el recuerdo de una marca identitaria, de un alma que se convierte, según Butler, en "un ideal normativo y normalizador conforme al cual el cuerpo es adiestrado, moldeado, cultivado e investido; (...) un ideal imaginario históricamente específico conforme al cual se materializa el cuerpo" (2011, p. 103). Secuela identitaria que no es otra que la prenda de la punición, de la violencia ética que naturaliza el poder de castigar en el cuerpo de los indisciplinados y sus prójimas. La "función psi" del internamiento penitenciario, así como vienen a confirmar los "avisos" del discurso punitivo durante todos los injertos disciplinares desde la escuela hasta el trabajo, interpela las estelas de la trayectoria de vida la pequeña célula familiar. A partir del hecho del encarcelamiento se hace funcionar la realidad como poder, imputando de las indisciplinas, de la desviación al cuerpo completo de la célula familiar, ahí donde se ha engendrado la monstruosidad de la que han de hacerse responsables todos y cada uno, personal y colectivamente. Zona gris de las marcaciones y los desmarques, de las herencias y los injertos, intensificando una realidad que se un embrollo que los va a ocupar a lo largo del encierro, y por qué no, a lo largo de toda su existencia. Un grave problema porque como la célula germina en cada uno de sus miembros, la marcación sobre cualquiera de ellos hace sinécdoque sobre el resto, por tanto, cuando encarcelan a uno los demás han de "ser como el encarcelado".

Expresión de una anatomía política donde la cárcel como último escalafón de la pirámide disciplinar, ya lo dijo Foucault, borra "lo que puede de haber de arbitrario en el poder legal y lo violento del poder disciplinar, atenuando los efectos de rebelión que ambos pueden suscitar" (2015, p. 355). A las familiares se las juzga "por ser como son, iguales a sus encarcelados", y se las interpela en forma de juicio, "en la misma medida que se ha difundido el poder normalizador (...) la actividad de juzgar se ha multiplicado" (2015, p. 355). Se las juzga desde una distancia moral que entronca con la relación establecida entre quien juzga y quien es juzgado, diferencia ontológica que hace eco en la escalinata de la pirámide disciplinar, un eco de veredictos, como expusiera Butler, en el que "nos apoyamos (...) para resumir la vida de otro, y confundimos así a postura ética con la persona que juzga" (Butler, 2009, p. 65).

El juicio moral trabaja como un haz más del panoptismo. La familiar está asida a una mirada penalizadora que sobrescribe sobre su cuerpo evaluaciones y valoraciones. El panóptico también tiene su anatomía de conos y bastones punitivos, la mirada de un "microtribunal permanente" (Foucault, 2011, p. 142), constituido por los relevos que engranan la microfísica del poder de la institución penitenciaria, así como en el juicio extralegal de una sociedad que figura al interno como aquel que cometió una falta y, le viste con la personificación paroxística del "enemigo público". Relevos de una microfísica que van del criminólogo al vecino, de la custodia a la familia extensa, que atienden insidiosamente los modos de conducción de la existencia de los familiares sobre el mismo tejido escritural que valora y juzga la coreografía de los familiares.

La resonancia del juicio, sojuzga, vitupera a las familiares con la fuerza de las palabras y las sujeta a la sinécdoque instruyéndolos como irreconocibles (Butler, 2009, p. 68). Se juzga demandando la emergencia de una identidad individual coherente con la sinécdoque, lo que fomenta que "la estructura narrativa de dar cuenta de mí misma sea sustituida por la estructura de interpelación 
en la cual se produce" (Butler, 2009, p. 59). Las miradas y los comentarios del jurado extrajudicial permanente, de cada uno de nosotros, van reembolsando la deuda del familiar en el cuerpo de las familiares. "Tu papá es un secuestrador", queda grabado a fuego en el cuerpo de una niña de 7 años, más cuando sus primos la dejan de hablar, cuando sus tíos y sus abuelos se borran, toman una distancia abismal con la célula familiar feminizada. Como señala Lazzarato:

El performativo de la promesa implica y presupone una 'mnemotécnica' de la crueldad y una mnemotécnica del dolor, las cuales, como la máquina de la colonia penitenciaria de Kafka, escriben la promesa al reembolsar la deuda directamente en el cuerpo (2013, p. 47).

Entonces el efecto refamiliarizador aparece como una intermitencia de semáforos rotos en una vía de tránsito opulento. Destellos de instancias disciplinares que no son más que paliativos patriarcales de familia, familias apósitas lideradas por pastores del resentimiento -Iglesias, AAa los que acuden tanto para atender las vibraciones de baja intensidad que instalan el alma del juicio en sus cuerpos, buscando apoyos en los que transitoriamente amainar sus sojuzgamientos, sus escarnios, y sobrecargas afectivas, físicas y materiales.

\section{Referencias}

Adorno, T., y Horkheimer, M. (1969). La sociedad. Lecciones de sociología. Proteo.

Alvarez-Uria, F., y Varela, J. (1991). Arqueología de la escuela. La Piqueta.

Baratta, A. (2016). Criminología crítica y crítica del derecho penal. Siglo XXI.

Butler, J. (2009). Dar cuenta de sí mismo. Violencia, ética y responsabilidad. Amorrortu.

Butler, J. (2011). Mecanismos psíquicos del poder. Teoría sobre la sujeción. Amorrortu.

Deleuze, G. (2013). Nietzsche y la filosofía. Anagrama.

Deleuze, G. (2013). El saber. Curso sobre Foucault, Tomo I. Cactus.

Deleuze, G. (2014). Conversaciones. Pre-Textos.

Engels, F. (2016). El origen de la familia, la propiedad privada y el estado. En K. Marx, y F. Engels. Obras escogidas. Vol. 2 (pp. 177-345). Akal.

Foucault, M. (2007). El poder psiquiátrico. Fondo de Cultura Económica.

Foucault, M. (2009). Vigilar y castigar Nacimiento de la prisión. Siglo XXI.

Foucault, M. (2011). La verdad y las formas jurídicas. Gedisa.

Foucault, M. (2016). La sociedad punitiva. Curso del College de France 1972-1973. Fondo de Cultura Económica.

Federici, S. (2004). Calibán y la bruja. Mujeres, cuerpo y acumulación originaria. Traficantes de sueños.

Ferreccio, V. (2018). El otro encarcelamiento femenino. La experiencia carcelaria de las mujeres familiares de detenidos. Revista Crítica Penal y Poder. 15, 43-70. https://raco.cat/index.php/CPyP/ article/view/343854

Goffman, E. (2006). Estigma. La identidad deteriorada. Amorrortu.

Herrera Urízar. G. C. (2019). El cuerpo disciplinado y el ocaso de la libertad: Análisis del hospital psiquiátrico y la escuela en el pensamiento de Michel Foucault. Sincronía 75, 104-120. https://doi.org/10.32870/ sincronia.axxiii.n75.5a19

Hoyos, P. (2021). Luciérnagas post-cana, Visibilidades de la máquina de escritura penitenciaria a través del dibujo. En M. Aguiluz, C. Ortega, y P. Hoyos. (Eds.). Comparecen los cuerpos: materias y fronteras (pp. 145-170). Universidad Nacional Autónoma de México, Centro de Investigaciones Interdisciplinarias en Ciencias y Humanidades. 
Irigaray, L. (2010). Ética de la diferencia sexual. Ellago.

Lagarde, M. (2015). Los cautiverios de las mujeres. Madresposas, monjas, putas, presas y locas. Siglo XXI y Universidad Nacional Autónoma de México.

Lazzarato, M. (2013). La fábrica del hombre endeudado. Ensayo sobre la condición neoliberal. Amorrortu.

López Petit, S. (2009). La movilización global. Breve tratado para atacar la realidad. Traficantes de sueños.

Lorey, I. (2016). Estado de inseguridad. Gobernar la precariedad. Traficantes de sueños.

Mendieta, E. (2021). Poder y subjetivación en Michel Foucault. Desde el Sur, 13(1), 1-11. http://dx.doi. org/10.21142/des-1301-2021-0015

Nietzsche, F. (2019). La genealogía de la moral. Alianza Editorial.

Pavarini, M. (2016). Control y dominación. Teorías criminológicas burguesas y proyecto hegemónico. Siglo XXI.

Ramírez Zuluaga, L. A. (2015). El sujeto en los juegos del poder: subjetivación y desubjetivación desde Foucault. Revista de Psicología Universidad de Antioquia, 7(2), 133-146. https://revistas.udea.edu.co/ index.php/psicologia/article/view/325209

Simmel, G. (2016). Filosofía del dinero. Paidós.

Wacquant, L. (2010). Castigar a los pobres. El gobierno neoliberal de la inseguridad social. Gedisa.

White, H. (2001). Metahistoria. La imaginación histórica del siglo XIX. Fondo de Cultura Económica.

\section{AUTOR}

Pablo Hoyos González. Profesor Invitado Tiempo Completo en el Departamento de Psicología Social, Universidad Autónoma Metropolitana, Iztapalapa. Es doctor en Psicología Social (mención Cum Laude), por el programa de Estudios de Posgrado de Psicología Social de la Universidad Autónoma de Barcelona. 